\title{
The Duality of Demand on University Libraries
}

$\mathrm{T}^{\mathrm{n}}$ HE FOLLOWING three papers and comments were presented at the meeting of the University Libraries Section, A.C.R.L., at San Francisco, July I, 1947.

\section{By M. A. STEWART}

\section{Educational Trends}

$\mathrm{T}_{\mathrm{t}}$ HE most obvious current educational trend at the college and university level is that of enormously increased numbers of students. This increase is by no means a postwar phenomenon, although it has been greatly augmented since the close of the recent war. The per cent of the population in the United States between eighteen and twenty-four years of age attending college has steadily increased from about 2 per cent in 1910 to approximately 8 per cent in 1940. In certain sections of the country, the increase has been even more spectacular. In California, for example, the increase in college attendance in the same population segment during the same three decades was from approximately 3 per cent to about 15 per cent. Since 1940 college and university enrolment has been characterized by a great slump consequent upon the draft and enlistment of young men of college age during the war years and the subsequent unprecedented high enrolments resulting from the backlog of students whose education had been interrupted by a period of service in the armed forces and from financial encouragement afforded by the so-called G.I. Bill of Rights. The Veterans Administration predicts that the peak veteran load will be reached in the academic year 1949-50.

It is difficult to predict college student populations of the future. The trend of the past three and a half decades is significant. The current increase presents the same significance. It is reasonable to assume that college attendance engenders college attendance and, therefore, that an increasing number, up to a heretofore unattained level, of young men and women will seek a college education. The increasing number of undergraduates and the modern demands of employers of college trained people will surely result in proportionate increase in graduate students. The most perplexing factor to be considered in predicting college attendance in the notdistant future is the economic depression so confidently anticipated by many competent economists. The precise nature and magnitude of such a depression and the techniques employed in combating it will determine to a large degree college enrolment during the period of economic distress. The writer does not pretend to possess the wisdom necessary to predict with any degree of accuracy the impact upon colleges and universities of this probable depression. However, it seems certain that there will be an impact which will either appreciably increase or decrease, temporarily, college attendance.

Another educational trend is to be seen in the recent establishment of auxiliary campuses, or even separate institutions, to ac- 
commodate the greater number of students and the tendency, in some parts of the country, at least, for junior colleges to add to their two-year terminal curricula provisions for more advanced education leading even to the bachelor's degree.

Some years ago Robert M. Hutchins, of the University of Chicago, postulated in an article written for The Saturday Evening Post that many of the small, privately endowed colleges and universities might have to consolidate or might disappear. His opinion was based upon the increased economic support and facilities given to statesupported institutions of higher learning, the changed economic structure which inhibits great gifts of money from individuals to privately-supported institutions, and modern transportation facilities which permit students to travel more widely and easily and thereby to select more freely the colleges they attend. Chancellor Hutchins' ideas are still valid, despite the currently inadequate educational facilities at the college level.

\section{Development of General Education}

Still another educational trend of great import is the current interest in the development of general education for all college students, regardless of their individual goals of specialization. This movement was greatly stimulated by the Harvard study leading to the publication of the book entitled General Education in a Free Society. It has received continued impetus by the spreading recognition that the needs and demands of society and state must be met by the institutions of higher education by providing not only highly trained young men and women but well-educated ones as well. Currently, the University of California is studying a proposal to establish a general college for all freshmen and sophomores in the university and to permit them to enter more specialized curricula only as upper classmen.

A fourth educational trend of particular concern to college and university librarians is the disproportionate increase in numbers of students specializing in the social sciences, particularly economics and business administration, political science, and sociology. This is occurring, despite the current interest in chemistry, engineering, and physics.

In interpreting the educational trends presented above with reference to library service demands and needs, it is obvious that the increase in numbers of students, the possible increase in numbers of institutions of higher learning or geographically distributed subdivisions thereof, and the potential expansion of junior college curricula give rise to urgent problems of greatly increased library space and personnel and augmented volumes or substitutes therefor, such as microfilms. Widespread adoption of curricula in general education will further increase these needs, consequent upon more use by more students of the general university library in conformance with requirements of a more liberal education. The increase of specialization in the social sciences will result in more students using more different kinds of publications.

Consideration of the impacts of current educational trends upon libraries and library services involves not only increments of space, personnel, and volumes, but also such fundamental administrative concepts as segregation or integration of services for undergraduates in different curricula and the separation of library functions for undergraduate and graduate students. Questions arising from such problems can better be asked than answered by one with no training or experience in librarianship. The acceptability of proposed procedures is determined by the feasibility of the recommendations. It can be argued strongly that 
the responsibilities of educational institutions to society demand fairly early segregation of students in accordance with their intellectual capacities and their professed goals. Thus, one may readily accept the concept of segregation of certain students into the junior college system with its socalled terminal curricula and of others into exclusively technical curricula without implications of broader appreciations and scholarly pursuits. This, however, does not connote segregation of library services, but different libraries. The trend in the larger universities, as well as in the smaller liberal arts colleges, toward general education during the freshman and sophomore years and the acknowledged responsibilities of such institutions to produce educated leaders emphasize integration, not segregation. No one will deny that colleges and universities have failed largely to acquaint their students with the great esthetic and utilitarian resources of libraries. Most college graduates are deplorably ignorant of the real functions of libraries and of how to avail themselves of their services. This means that adequate library environments have not been provided. Therefore, one of the urgent challenges to the university library is to provide such an environment. It would appear that this need can be met better by integration than by segregation.

\section{Different Library Needs}

The separation of library functions for undergraduate and graduate students is very different from the integration or segregation of library services for undergraduates.
Graduate students have library needs which are different from those of the undergraduate, and their approaches to library utilization are different. Certain separation is inevitable and its extent seems to be largely a matter of expediency.

A discussion such as this merely presents the question as to how the university library can afford the greatest service of permanent value to the student. If we may agree that the first step in this direction is the provision of an adequate library environment, we must then ask ourselves whether or not universities can provide an introduction to the knowledge of libraries and indoctrination into their use, as is done in the best liberal arts colleges. If not, is this need to be ignored or can we devise some new technique that will provide for it? It is the opinion of the writer that we can rely but little, if at all, upon the secondary schools for assistance and that faculties must be indoctrinated by librarians and be expected to cooperate subsequently with them in meeting the need at hand. Probably there is widespread general agreement among librarians and faculty members as to what the ideal university library would be but great disagreement as to procedure for attaining it and particularly with reference to acceptable substitutes for the ideal. It is appropriate, therefore, to urge that the experimental method, based upon sound analysis and speculation, be employed in finding a way to meet the legitimate demands placed upon university libraries and in seeking the adjustments consequent upon current educational trends. 


\section{By KEYES D. METCALF}

\section{To What Extent Must We Segregate?}

TCHE "must" in this title was placed there 1 by your chairman and not by your speaker. The argument would be clearer if it were replaced by "should."

If I had to answer the question in one sentence, I would say it depends on local conditions. But that is dodging the question, so I will go on and summarize the rest of my paper by saying that in a large university library, such as we have at Harvard, we should segregate to a great enough extent to make it possible to give the undergraduate students reasonably good library service, service such as an undergraduate can now have at Oberlin, Williams, Wellesley, Wesleyan, or almost any good college. I must go on to say that such a service is available in few, if any, of our great university libraries today, in spite of the tremendous sums spent on them. An explanation of the cause of this state of affairs should be given. When the two groups, graduate students and faculty-you might call them research workers-and undergraduate students, compete for services in the same building, with the same collections and catalogs, the undergraduates are almost always the ones who suffer. To this should be added the fact that the undergraduate in the university library does not have readily at his disposal, with open access, a good general collection of considerable size and that he must use the great confusing collections of the library with the help of a very complicated, unwieldy, labyrinthian catalog which has been made with the advanced student in mind and which frequently is almost unintelligible to the graduate student and to the faculty as well. Let me interpolate at this point that Princeton, with a great library but catering to a larger extent than most university libraries to undergraduates, is trying to combine in its new building, library facilities for the two groups. It will be interesting to see how successful the results will be, but it should be noted that Princeton has a much simpler problem on its hands than a university with three to ten times as many students.

I might rest my case at this point, but having summarized my argument I shall begin again and try to steal some of the next speaker's thunder by two more general statements.

I. Of course we must integrate the services, he will tell us, because the needs of the two groups overlap and cannot be segregated.

2. Also, of course we must segregate or at least decentralize. Don't we have reserved book shelves?

But I must go on and state:

I. If we segregate, the undergraduates must be allowed and encouraged to use the research library facilities when they need them and, if they are going to do graduate work, they must be made, if that is possible, to do so.

2. Even if we integrate, we must have separate rooms for rare books and certain other collections.

Before going on and arguing for segregation, let us consider just what it is that a library tries to do. It tries to give as good service as it can afford. Then let me add, it should not afford more than can be justified. A library can become so expensive as to handicap the other parts of a university program and thus become, among other things, unpopular enough with the university family as a whole to handicap seriously its own work. A new central university library building at Harvard, at 
present-day prices, would cost somewhere between fifteen and twenty million dollars. The interest at 4 per cent on the lower figure would be $\$ 600,000$ a year. The physical upkeep for the building would be at least $\$$ I50,000 more. I would be unwilling to claim that under present conditions that would be the best way for Harvard to spend $\$ 750,000$ in new money each year, even if it had it to spare, which it does not.

\section{Service to Undergraduates}

But to go back to our statement, a university library tries to give as good service as it can afford. What should good library service to undergraduates provide? Three things among others: a library as conveniently located as possible; centralized so that undergraduates who work, as most of them do, in different fields can find material under one roof in all of the subjects in which they are interested; a library easy to use, which involves simple catalog, classification, and charging systems, and rapid service. All this should be under attractive, you might say tempting, conditions.

If my argument for segregation of service to undergraduates is valid, it means that the service to undergraduates just outlined can be given more satisfactorily and for less money when it is segregated from service to graduate students than when it is integrated with it. Let us consider this from two points of view: the cost of the service and the quality of the service.

I contend that the cost will be less with segregation because:

I. This logical separation of the units of the library enables the university to add to its building plant in small units and so make less necessary over-expansion when a new building is erected.

2. The division of the book stock into two fairly distinct groups, one for the undergraduates which is made up largely of re- placeable and what might be called expendable books, and the other for research material, makes it possible to be more efficient and less wasteful in both groups.

3. The segregation permits cheaper and simpler cataloging and classification procedures for the undergraduates books, and also I think it will apply to the research collection. When you catalog books for two different groups who use them for entirely different purposes, it must be done in more detail and it therefore costs more.

4. The service required by the two groups differs enough so that if the total public service staff is fairly large, it is cheaper to divide it into two.

The savings made possible by segregating in a university library the service to undergraduates from that for graduates students, is in my opinion important, but the improvement in the service that results from the segregation is of equal and probably of greater importance. It seems self-evident that if a building is designed especially for undergraduate service, it will be more effective than if it is designed to do all things for all men. It can, for instance, among other things, give completely free access to the book collection, if the books are segregated from the research library. If the book stock is a separate unit and is chosen by a person specially trained in that phase of book selection, it should be better fitted for undergraduate use. If the catalog is simple, as is possible with a separate collection, the results are again better, and the same should hold true with the reference and circulation part of the work. The service demanded by the two groups differs considerably, and that planned for one of the groups should be better than that planned to cover both.

\section{Better and Cheaper Service}

I end where I began. No great university library today gives good service to its undergraduates. The two types of service do not fit together and one or the other 
of them gets the better of it. In my opinion, it is almost inevitable that it is the undergraduate who gets the worst of the deal. By separating the groups, better and cheaper service is obtained.

Two final comments: just where the division should come, that is, in what stage of the student's development, is a matter of importance but not first importance; and, finally, as I said to start with, if segregation is carried out, arrangements must be made so that the undergraduate will still have at his disposal if he wants it the larger collection and catalog.

By RALPH E. ELLSWORTH

\section{To What Extent Can We Integrate?}

\section{$\mathrm{I}^{\mathrm{F}}$} THE TERMS "undergraduate" and "graduate" must be defined traditionally, I can see no possible basis for establishing two separate library collections which would serve undergraduates as such and graduates as such. There is no such thing anymore as a graduate student or a graduate curriculum that can be characterized by singleness of activity. Examine the transcripts of graduate students or the class rolls of the group of courses commonly labeled the IOo's, and you will find in this twilight zone an equal mixture. Where are the books for these courses to go in a library which splits between graduate and undergraduate?

Actually, the graduate school is moving in two directions. In the traditional disciplines and even in some of the newer fields, there is a growing distinction between the research and nonresearch degree for graduate students. What this means, of course, is that many students need graduate training and graduate degrees for a wide variety of reasons but that all do not need training in pure or even applied research. Some need more courses, others need supervised experience, and some need merely to age. Those who at the graduate level are to spend their time on nonresearch activities such as taking courses or coordinating the results of research will inevitably work in the same literature that is being used in the advanced undergraduate courses. There is no logical basis for separating this material.

Or, to look at the same fact from another direction, it is possible to argue that the American graduate college is primarily though not exclusively a teacher-training institution. Certainly a very large per cent of its graduates go into teaching at the various levels. Some who go into teaching will continue to do productive research; most will not. But all should know how to interpret the research of others. We have been pretending that all will continue their research careers. There are signs that we are ready to stop some of this pretense and begin to approach directly the problem of developing graduate training for nonresearchers. If we do, then the latter group will surely increase its use of secondary material, which is the same as that used in the advanced undergraduate courses.

Thus, my first argument is that graduate education is moving in a direction which will complicate any attempt to separate its literature from that of lower instructional units.

My second is that the undergraduate college is no longer a single unified curriculum demanding a single library facility.

For years (in fact it dates from the in- 
flux of students into colleges following World War I) it has been true that a large per cent ( 40 to 60 ) of entering freshmen have dropped out of college before the end of their four-year term. Those who drop out find that a segment of liberal arts curriculum by itself is likely to be pretty meaningless. Thus, as a corrective measure, what the colleges have been trying to do is to devise a small curriculum of required courses which would be equally useful to those who drop out early and others who stay on for the A.B. When you strip the term of its pretense, jargon, rationalizing, double talk, and verbiage, that is what is meant by general education.

Whether we like it or not, I think we shall find Gresham's Law operating, with the result that the traditional concept of a four-year liberal education will be driven out by the two-year idea of general education, with upper divisional studies in control of the graduate school or the professional schools.

You can see that general education is splitting our educational pyramid at a new level-in the middle of the arts college, not at its end. Symbolic of this trend is the fact that the office of arts college dean is disintegrating in many universities, and in its place influence is passing both downward to directors of general education and upwards to graduate deans or, in some cases, to chairmen of divisions which overlap the last two years of the arts college and the graduate school.

In the general education courses that have emerged one can see a desire to teach an irreducible minimum to all students, some common body of information that somehow will supply a cohesive element in our population of adults-something that in the province of democratic living would be as useful as is the dogma of the Roman Catholic Church to Catholics.

\section{Difference of Opinion}

Opinion differs as to what shall consti tute the contents of general education, with Chancellor Hutchins' idea about the Great Books at one end of the scale and a number of programs based on practical problems of everyday life at the other.

If the question were simply one of supplying the materials for these courses, it would be difficult to argue that separate facilities are necessary, but the materials are only a small part of the problem.

Entering students in liberal arts in all but a few Eastern seaboard universities whose students come from highly cultured homes and from prep schools that stand for no nonsense, have some deficiencies that are pretty common and that can be corrected most efficiently if the students work at least part of the time as an identifiable group. These deficiencies have been discussed in print sufficiently, and I need not labor the point. Briefly, they are as follows: lack of knowledge of study habits at the university level, lack of knowledge of the literature of scholarship and its bibliographic apparatus, lack of the ability to sit still and study in a sustained manner, and reluctance to ask for help on the above points.

If a separate study center can be established which will base its contents, staff organization, and bibliographic tools at the level at which general education students are, it is in a favorable position to accomplish something that doesn't get done in a library where all undergraduates are thrown together. What I have in mind is something like the college library at the University of Chicago, which used to be located in the midst of the instructional office of the men who were teaching college courses.

If general education should begin to shift away from the idea of a common sub- 
ject matter for all to the idea that it is only the student as an individual-his interests, personality, attitudes, working habits, vocational desires, etc.-that is common, with subject matter patterns varying among the individuals, then the need for a separate study center would still exist, but it would be more of an advisory or counseling service than it would be a collection of materials.

If I am right in claiming that general education represents a retreat from the old idea of liberal education (as, for example, Mr. Metcalf and I knew it at Oberlin), a further encroachment of specialized and professional education, then it should follow that in the junior and senior years there will be an increased emphasis upon specialized and professional studies, and that is exactly what happens.

Indicative of the trend is the statement made recently by the chairman of one of Chicago's most illustrious departments to the effect that his department was in favor of the Chicago college plan because it enabled them to organize a three-year major that really meant something. And by that, he meant a solid, comprehensive, and advanced preparation extending up through the master's degree. Would such a program be satisfied by a library that tried to divide the advanced literature of the field into graduate and undergraduate? I think not.

Obviously, as the relationship between advanced undergraduate studies and graduate work increases, it will be increasingly difficult to divide the literature between the two. Both groups draw heavily on the journal files, the government documents, the maps, and the ordinary books at least in the social sciences and the humanities.

\section{Segregation}

So, I have argued that segregation should be made for general education studies, but it cannot be made above that level. This does not mean that we can now build a big stack well and place in it all but a few thousand titles which are kept out for the general education' study center. We shall have to divide the advanced materials as we have in the past into departmental, divisional, and perhaps other kinds of units. But the point is that whatever we do will have to be done for both graduates and advanced undergraduates as a single group.

Special courses established on a civilization or geographic area basis are only two examples of the new pressures that will continue to exist for vertical segregation of library material.

Likewise, it seems to me that the problem of supplying library catalogs, bibliographic tools, and literature guides is an impossible one if it has to be approached in terms of graduate versus undergraduate facilities. But it becomes rational when considered in terms of general education versus advanced studies. Our present card catalogs are about as relevant to the needs and abilities of entering college students as would be the radar equipment found in a B-29 for a Piper Cub.

Young students need catalogs and guides which will draw them to the kind of print they are capable of using and which the faculty wish them to read. They should, of course, begin to learn to use the more complicated guides as soon as possible, but as a separate activity. Conversely, the catalogs and guides for advanced students, the middle man, and the researcher, should omit the elementary references that are irrelevant to their work. I am talking about subject catalogs, not identification catalogs, which are another matter.

I can see no logical basis for developing catalogs and bibliographies that would distinguish between the literature needed by 
advanced undergraduate and graduate students.

\section{Special Kind of Librarian}

The same principles govern the kind of library staff that a university library should have. It takes a very special kind of librarian to understand and know how to cultivate young college students' reading habits so that they are consistent with the objectives of the instructors. Such a librarian must know the techniques of remedial reading and much else in addition to his knowledge of the books in his collec tion. He must like the young student with all his annoying but lovable traits.

But the research librarian should be a quite different sort of person, and, as you well know, has to deal with other kinds of problems.

In summary, I have argued that we can and must integrate the collections, bibliographies, and staff services for advanced work but that we should segregate the facilities at present used by young students in our colleges.

By ROBERT A. MILLER

\section{Comments}

$\mathrm{I}^{\mathrm{T}}$ T IS DIFFicult to find matter for critical comment in these three sensible papers. In each there is a willingness to consider segregation of library materials for the convenience of undergraduates. Only with respect to when to segregate is there a difference in the positions taken by $\mathrm{Mr}$. Metcalf and Dr. Ellsworth. The latter maintains that segregation is defensible only through the second year of college, whereas $\mathrm{Mr}$. Metcalf believes that segregation is defensible for a four-year program of undergraduate study always with the provision that the central or research collection should be available to the undergraduate.

It seems to me that the difference in the positions taken by Mr. Metcalf and Dr. Ellsworth arises, not out of different interpretations of educational philosophy or trends, but because of local needs and solutions. Specifically, Harvard is committed to a tutorial plan for the four-year undergraduate program. The reasonable and logical libräry solution is an undergraduate library. The programs of general or basic education under way in many institutions, with some manner of break at the end of the second year, suggest to Mr. Ellsworth segregation through the second year only. There are several university libraries in the country which have found a local solution in junior or lower division libraries and reading rooms.

If local needs and solutions, therefore, seem to suggest the answer to segregation, how does Dean Stewart contribute? He has emphasized the recent trend of growth and the problems that accompany growth. It is size that forces the university library to segregation-size of library collection or size of student body.

If we can visualize a student body of 75 freshmen, 60 sophomores, 50 juniors, 40 seniors, and 20 graduate students, and the library materials needed by these students during one year, it is clear that segregation is not needed. One library can serve all. This reasoning must prevail at Princeton for an appreciably larger student body than in my example.

The question of integration and segrega(Continued on page 42I) 